\title{
Threshold switching and electrical self-oscillation in niobium oxide films
}

Xinjun Liu', Shuai Li, Sanjoy Kumar Nandi, Dinesh Kumar Venkatachalam, and Robert Glen Elliman

Citation: J. Appl. Phys. 120, 124102 (2016); doi: 10.1063/1.4963288

View online: http://dx.doi.org/10.1063/1.4963288

View Table of Contents: http://aip.scitation.org/toc/jap/120/12

Published by the American Institute of Physics

\section{Articles you may be interested in}

The role of defects in the electrical properties of $\mathrm{NbO} 2$ thin film vertical devices

J. Appl. Phys. 6, 125006125006 (2016); 10.1063/1.4971818

\section{AlP $\left.\right|_{\text {Applied Physics }} ^{\substack{\text { Journal of } \\ \text { Ans }}}$}

INTRODUCING INVITED PERSPECTIVES

Ultrafast magnetism and $\mathrm{THz}$ spintronics

Authors: Jakob Walowski and Markus Münzenberg 


\title{
Threshold switching and electrical self-oscillation in niobium oxide films
}

\author{
Xinjun Liu, ${ }^{1, a)}$ Shuai Li, ${ }^{1}$ Sanjoy Kumar Nandi, ${ }^{1,2,3}$ Dinesh Kumar Venkatachalam, ${ }^{1}$ \\ and Robert Glen Elliman ${ }^{1}$ \\ ${ }^{1}$ Department of Electronic Materials Engineering, Research School of Physics and Engineering, \\ The Australian National University, Canberra, ACT 2601, Australia \\ ${ }^{2}$ Research School of Astronomy and Astrophysics, The Australian National University, Canberra, ACT 2601, \\ Australia \\ ${ }^{3}$ Department of Physics, University of Chittagong, Chittagong 4331, Bangladesh
}

(Received 30 May 2016; accepted 10 September 2016; published online 28 September 2016)

\begin{abstract}
Electrical self-sustained oscillations have been observed in a broad range of two-terminal systems and are of interest as possible building blocks for bio-inspired neuromorphic computing. In this work, we experimentally explore voltage-controlled oscillations in $\mathrm{NbO}_{x}$ devices with a particular focus on understanding how the frequency and waveform are influenced by circuit parameters. We also introduce a finite element model of the device based on a Joule-heating induced insulatormetal transition. The electroformed device structure is represented by a cylindrical conductive channel (filament) comprised of $\mathrm{NbO} / \mathrm{NbO}_{2}$ zones and surrounded by an $\mathrm{Nb}_{2} \mathrm{O}_{5-x}$ matrix. The model is shown to reproduce the current-controlled negative differential resistance observed in measured current-voltage curves, and is combined with circuit elements to simulate the waveforms and dynamics of an isolated Pearson-Anson oscillator. Such modeling is shown to provide considerable insight into the relationship between the material response and device and circuit characteristics. Published by AIP Publishing. [http://dx.doi.org/10.1063/1.4963288]
\end{abstract}

\section{INTRODUCTION}

Threshold switching devices and self-sustained electrical oscillators have attracted particular attention due to their potential for the applications as selector elements in emerging non-volatile memory and as building blocks for bioinspired neuromorphic computing, respectively. ${ }^{1-4}$ Among these, devices based on metal-oxide-metal (MOM) structures offer the advantage of device simplicity and scalability, and have been used to realize systems of nano-crossbar array memory and coupled nano-oscillators. ${ }^{3-6}$ The systems of particular interest in the present study display currentcontrolled negative differential resistance (CC-NDR), also called threshold switching, due to a thermally induced insulator-metal or metal-insulator transition (IMT/MIT).$^{7-9}$ The resistance change is dominated by a thermally transformed volume that changes from an insulating to a metallic state at high temperatures and returns to an insulating state when the temperature is lowered. In device operation, the transition is controlled by local Joule heating and the device switches between the insulating and metallic resistance states at particular voltages. Vanadium dioxide $\left(\mathrm{VO}_{2}\right)$ is a wellstudied prototypic material for the CC-NDR element in relaxation oscillators ${ }^{10-16}$ but unfortunately its low transition temperature $\left(T_{\mathrm{IMT}}\right)(\sim 340 \mathrm{~K})$ precludes its use in many microelectronics applications, where the expectation is that devices will operate at temperature approaching $400 \mathrm{~K}$. Recent interest has focussed on related IMT materials with higher transition temperatures, including $\mathrm{NbO}_{2}$ which has a transition temperature of $\sim 1073 \mathrm{~K},{ }^{17,18}$ extending the possible temperature range of applications.

${ }^{a)}$ Electronic addresses: tjuxjliu@yahoo.com and xinjun.liu@anu.edu.au
Although there are some early reports on $\mathrm{NbO}_{2}$ selfoscillation, ${ }^{19,20}$ Lalevic and Shoga first reported stable and reproducible oscillations with frequency up to $\sim 600 \mathrm{kHz}$ in single crystal $\mathrm{NbO}_{2}$ and polycrystalline $\mathrm{NbO}_{x}$ films in $1981 .^{21}$ Recently, several reports have highlighted the nonlinear current-voltage $(I-V)$ characteristics of electrically switched $\mathrm{NbO}_{x}$ thin films ${ }^{22-25}$ and the occurrence of $\mathrm{MHz}$ periodic oscillation signals maintained across two-terminal devices. ${ }^{7,26,27}$ Our previous study demonstrated the electrical self-oscillation with a frequency of tens of $\mathrm{MHz}$ in a $\mathrm{Ti} / \mathrm{NbO}_{x}$ NDR device with low operation voltages, large frequency control range, and long endurance. ${ }^{26} \mathrm{~A}$ unique feature of these IMT-based oscillators is that they do not require any inductive elements or transistors as required in conventional electrical oscillators. ${ }^{7}$ The oscillation frequency can also be tuned over several orders of magnitude by controlling the source voltage or load resistance. ${ }^{5,6}$ These features are particularly attractive for making scalable, low-power devices.

The threshold switching mechanism in amorphous $\mathrm{NbO}_{x}$ films remains unclear, with recent discussion centering around two mechanisms: one based on the thermally induced IMT in crystalline $\mathrm{t}-\mathrm{NbO}_{2},{ }^{7,17}$ and the other, a purely electronic model, based on the temperature dependence of PooleFrenkel (PF) conduction. ${ }^{28-30}$ Both models assume that switching occurs along a filamentary path created during electroforming and results from a reduction in electrical resistivity with the increasing temperature due to local Joule heating. The difference is the basis of the resistivity change, which in one case is a thermally induced IMT and in the other is an increase in trap-assisted carrier transport. Since the IMT is specific to crystalline $\mathrm{NbO}_{2}$, it has been speculated that a polycrystalline $\mathrm{NbO}_{2}$ zone or filament is created by the 
electroforming process and that this is responsible for the IMT response. $^{31-33}$ This is not unreasonable given the high local temperatures $(>1073 \mathrm{~K})$ associated with the electroforming process, and indeed, it has recently been confirmed experimentally for films subjected to high forming currents. ${ }^{29,34,35}$ It is also interesting to note that the limited number of transition metal oxides (TMOs) that exhibit reliable threshold switching (e.g., $\mathrm{TiO}_{x}, \mathrm{VO}_{x}$, and $\mathrm{NbO}_{x}$ ) also have crystalline phases that exhibit thermally induced IMTs. ${ }^{8}$ Various combined phase structures of $\mathrm{NbO}, \mathrm{NbO}_{2}$, and $\mathrm{Nb}_{2} \mathrm{O}_{5-x}$ have been proposed to result from electroforming, ${ }^{34}$ including structures comprised of a $\mathrm{NbO} / \mathrm{NbO}_{2}$ current channel. ${ }^{24}$ The threshold switching response will be clearly influenced by such microstructure.

Here, we investigate the self-oscillation behavior of $\mathrm{NbO}_{x}$ threshold switching devices and introduce a finiteelement model of threshold switching that accounts for the CC-NDR response of devices and provides the basis for studying the relationship between the materials response and oscillator dynamics. The model is based on a Joule-heating induced IMT in $\mathrm{NbO}_{2}$, with the electroformed device structure represented by a $\mathrm{NbO} / \mathrm{NbO}_{2}$ current channel (filament) surrounded by an oxygen-deficient $\mathrm{Nb}_{2} \mathrm{O}_{5-x}$ matrix. The model is extended to include the effect of circuit elements in a simple Pearson-Anson electrical circuit and shown to capture the periodicity and waveform of device currents and voltages as a function of the circuit parameters. These simulations provide an in-depth understanding of the nature of oxide oscillators and their dependencies.

\section{EXPERIMENTAL AND SIMULATION METHOD}

\section{A. Devices}

$\mathrm{Pt} / \mathrm{Ti}(10 \mathrm{~nm}) / \mathrm{NbO}_{x} / \mathrm{Pt}$ test structures were employed for this study, as shown in Figure 1(a). To fabricate devices, a $100 \mathrm{~nm} \mathrm{Si}_{3} \mathrm{~N}_{4}$ was first deposited on a $\mathrm{Si}$ substrate by plasma-enhanced chemical vapour deposition (PECVD) at $300{ }^{\circ} \mathrm{C}$. Pt $(50 \mathrm{~nm})$ bottom electrodes (BEs) were then deposited on the $\mathrm{Si}_{3} \mathrm{~N}_{4}$ by electron beam evaporation. Note that the $\mathrm{Si}_{3} \mathrm{~N}_{4}$ surface was cleaned in-situ by Ar-ion bombardment prior to $\mathrm{Pt}$ deposition to obtain good adhesion between $\mathrm{Pt}$ and $\mathrm{Si}_{3} \mathrm{~N}_{4}$. (This was checked by the scotch-tape test before and after annealing up to $500{ }^{\circ} \mathrm{C}$.) $75 \mathrm{~nm}$ thick films of $\mathrm{NbO}_{x}$ oxide were deposited onto the Pt BEs at room temperature using reactive sputtering from a metallic niobium target, in which the stoichiometry was controlled by the ratio of argon to oxygen (18/2 at $20 \mathrm{sccm})$ at a constant total pressure of $4 \mathrm{mTorr}$ and constant power of $150 \mathrm{~W}$. Patterned top electrodes $(150-250 \mu \mathrm{m}$ in diameter) were then deposited through a shadow mask by e-beam evaporation in a vacuum better than $10^{-6}$ Torr. These comprised a $\sim 10 \mathrm{~nm}$ Ti layer followed by a $50 \mathrm{~nm}$ Pt layer to provide more robust contact pads and to protect the Ti from oxidation. After fabrication devices were subjected to a rapid thermal anneal at $300{ }^{\circ} \mathrm{C}$ for $5 \mathrm{~min} . \mathrm{Pt} / \mathrm{Nb}(10 \mathrm{~nm}) / \mathrm{NbO}_{x} / \mathrm{Pt}$ structure was also fabricated and annealed under the same condition.
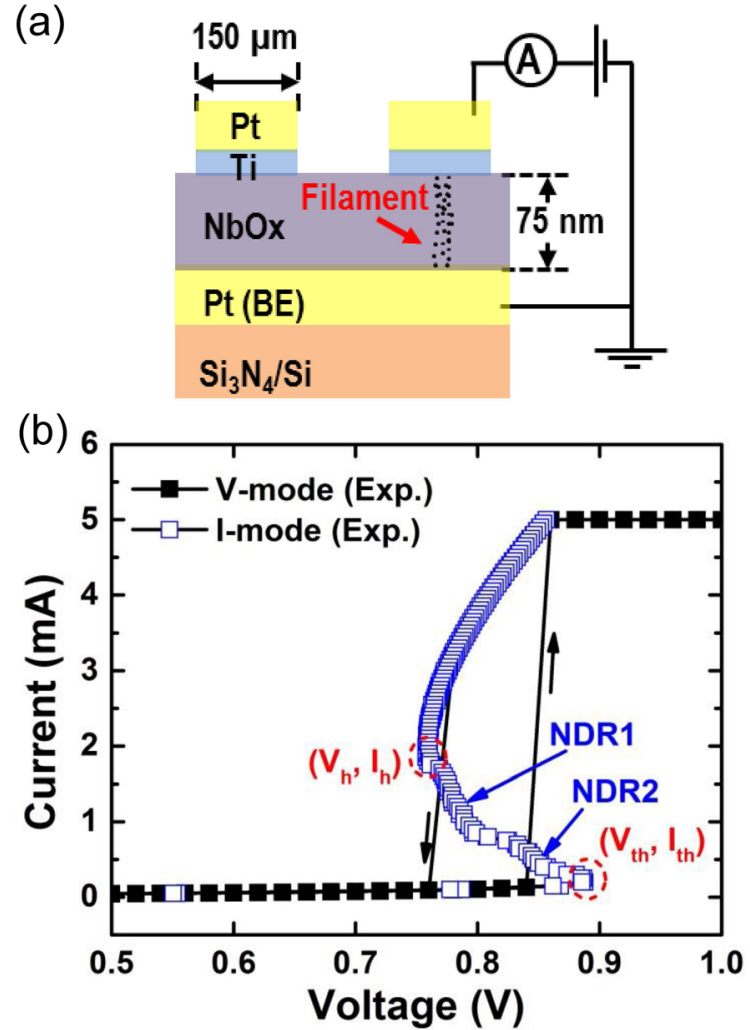

FIG. 1. (a) Schematic of the fabricated $\mathrm{Pt} / \mathrm{Ti} / \mathrm{NbO}_{x} / \mathrm{Pt}$ test devices and the measuring conditions. (b) Measured $I-V$ curves for both voltage- and current-sweeping modes, showing a clear CC-NDR characteristic with multi-NDR properties.

\section{B. Characterization}

The stoichiometry of the $\mathrm{NbO}_{x}$ layers was determined by the electron Rutherford backscattering (eRBS) technique ${ }^{24,36}$ and $\mathrm{X}$-ray diffraction confirmed that they were amorphous, both as-deposited and after annealing at $300{ }^{\circ} \mathrm{C}{ }^{37}$ Electrical measurements were carried out in air using an Agilent B1500A semiconductor parameter analyser attached to a Signatone probe station. Rectangular voltage pulses were generated with a Waveform Generator/Fast Measurement Unit (WGFMU) as part of the B1500A analyser, and the resulting electrical response was recorded by monitoring the voltage drop across the $50 \Omega$ resistor using a Tektronix TPS2024B oscilloscope.

\section{Numerical calculations}

Finite-element simulations of Joule heating in the $\mathrm{NbO}_{x}$ film are performed using the COMSOL Multiphysics software by coupling electric current (ec) and heat transfer in solids (ht) physics modules. DC switching characteristics were calculated by assuming an increasing voltage/current sweep with positive sign for insulator-metal transition. Subsequently, the two dimensional axis-symmetric model of the $\mathrm{NbO}_{x}$ film that acted as a resistive element is further coupled with electrical circuit (cir) module included with the DC supply, load resistor $\left(R_{L}\right)$, and capacitor $(C)$. The full model is solved self-consistently to capture the circuit response to any parameter change. 


\section{ELECTRICAL SWITCHING AND DYNAMICS PROPERTIES}

The as-deposited $\mathrm{NbO}_{x}$ film was amorphous and remained so after annealing. ${ }^{37}$ Threshold switching behaviour and electrical self-oscillation were only observed after an initial electroforming step in which the device was subjected to a negative voltage sweep to induce soft breakdown. ${ }^{26,37}$ Given that a Ti electrode is used in the present study, it is also important to note that self-oscillation behaviour has been observed in polycrystalline $\mathrm{TiO}_{2}$ thin films in $\mathrm{Ti} / \mathrm{TiO}_{x} / \mathrm{Cr}$ device structures. ${ }^{38}$ To assess the effect of titanium suboxides in the present case, $\mathrm{Pt} / \mathrm{Nb} / \mathrm{NbO}_{x} / \mathrm{Pt}$ device structures were characterised for comparison. These devices exhibited similar threshold switching and self-oscillation behaviour after an initial electroforming step (see Figure S1 in the supplementary material), suggesting that threshold switching is due to $\mathrm{NbO}_{x}$.

\section{A. I-V response}

The $I-V$ response of $\mathrm{Ti} / \mathrm{NbO}_{x}$ devices is shown in Figure 1(b) for both voltage- and current-controlled sweeping modes, clearly highlighting the threshold switching response and CC-NDR. In the low applied current range from 50 to $200 \mu \mathrm{A}$, the voltage is observed to increase continuously; the device is in high resistance state, i.e., "off" state. When the applied current surpasses the threshold current $\left(I_{t h} \sim 0.2 \mathrm{~mA}\right.$-labelled B) the voltage starts to decrease continuously, with an onset voltage for the NDR at $\sim 0.88 \mathrm{~V}$, called the threshold voltage $\left(V_{t h}\right)$. This corresponds to the onset of the IMT transition and the device continues to exhibit NDR until the current is increased to the hold current $\left(I_{h} \sim 2.1 \mathrm{~mA}\right.$-labelled D), which corresponds to saturation of the metallic phase volume at $\sim 0.75 \mathrm{~V}$, called the hold voltage $\left(V_{h}\right)$. After this, the voltage increases monotonically as the current increases, with the device in a low resistance (metallic) state, i.e., "on" state. As indicated in Figure 1(b), multi-NDR regions are evident in the $I-V$ curves, similar to those observed in $\mathrm{VO}_{2}$ devices. ${ }^{11,39-41}$ In the $\mathrm{VO}_{2}$ case, it was suggested that the emergence of these NDR regions resulted from the progressive development of the IMT in the oxide material, where metallic nano-domains within the oxide matrix grow gradually and semiconducting and metallic domains co-exist in the oxide films. ${ }^{11,41}$ Similar effects can be expected in the case of $\mathrm{NbO}_{x}$ films with intrinsic material inhomogeneities after the electroforming step.

\section{B. Self-oscillation}

Switching dynamics and the ability to generate selfsustained oscillations were investigated for the $\mathrm{Ti} / \mathrm{NbO}_{x}$ device by integrating it into an electrical circuit similar to a Pearson-Anson relaxation oscillator with the MOM device acting as the CC-NDR element. ${ }^{7,26,42}$ A schematic diagram of the electrical circuit used for the generation of the IMT/ MIT electrical oscillation is shown in Figure 2(a). It consists of a pulsed voltage supply, a load resistor $\left(R_{L}\right)$, a $50 \Omega$ monitoring resistor and the CC-NDR device under test. The input voltage pulse $\left(V_{S}\right)$ and the voltage across the $50 \Omega$ resistor
$\left(V_{50 \Omega}\right)$ during voltage excitations were monitored using a Tektronix TPS2024B oscilloscope. The series resistor $R_{L}$ modifies the $\mathrm{Ti} / \mathrm{NbO}_{x}$ IMT dynamics through negative feedback, and to achieve oscillation, the external resistance, $R_{L}+50$, should be larger than the critical resistance: ${ }^{5} R_{C}$ $=\frac{V_{t h}-V_{h}}{I_{h}-I_{t h}} \sim 70 \Omega$. Load line analysis ${ }^{26,43}$ shows that the voltage window for stable oscillation is from $V_{S, \min }$ to $V_{S, \max }$, where $V_{S, \text { min }}=V_{t h}+\left(R_{L}+50\right) I_{\text {th }}$ and $V_{S, \text { max }}=V_{h}+\left(R_{L}+50\right) I_{h}$.

A 2- $\mu$ s-long bias pulse with the voltage amplitude in the range of $\left(V_{S, \min }, V_{S, \max }\right)$ was applied, during which voltage oscillations across the $\mathrm{Ti} / \mathrm{NbO}_{x}$ device were observed. ${ }^{26}$ With $R_{L}$ of $1 \mathrm{k} \Omega$, load-line analysis indicates that voltage generation window is $(1.1,2.9) \mathrm{V}$. Figure 2(b) shows the measured device current $\left(I_{\text {Device }}=I_{50 \Omega}=V_{50 \Omega} / 50\right)$ at various $V_{S}$ values ranging from 1.0 to $2.8 \mathrm{~V}$. Three features are evident: (a) Sporadic oscillations with an ill-defined period for $V_{S}$ around $1.17 \mathrm{~V}$, which is the threshold for inducing the IMT in the $\mathrm{NbO}_{2}$ zone or filament. Interestingly, even when using the same operation conditions, a different number of peaks is observed (see Figure S2 in the supplementary material), an effect related to the stochastic nature of the switching process and intrinsic material inhomogeneities; (b) stable relaxation oscillation for $V_{S}>1.17 \mathrm{~V}$, which is the most interesting feature for many applications; ${ }^{2-4}$ and (c) damped oscillations for $V_{S} \geq 2.6 \mathrm{~V}$, where the $\mathrm{NbO}_{2}$ zone tends to remain in the metallic state during the pulse period. This damped oscillation is typical for a circuit with CC-NDR elements when the source voltage is close to the upper limit. These features can also be observed for different $V_{S}$ with $R_{L}=500 \Omega, 2 \mathrm{k} \Omega$, and $4 \mathrm{k} \Omega$, as shown in Figure $\mathrm{S} 3$ (supplementary material).

The frequency of the $\mathrm{NbO}_{x}$ oscillator was observed to increase as $V_{S}$ increased, ${ }^{5,10,26}$ with a voltage tuning sensitivity of $f_{O s c}$ from $22.6 \mathrm{MHz} / \mathrm{V}$ with $R_{L}$ of $0.5 \mathrm{k} \Omega$ to $2.5 \mathrm{MHz} / \mathrm{V}$ with $R_{L}$ of $4 \mathrm{k} \Omega$. Besides $V_{S}$ and $R_{L}$ in this experimental configuration, the frequency was also controlled by the intrinsic device capacitance $\left(C_{\text {Device }}\right)$ and the parasitic capacitance $\left(C_{P \text { arasitic }}\right)$, where the latter arises from the measurement system, i.e., coaxial cables, the voltage source, and probes.

Figure 2(c) shows typical device current $\left(I_{\text {Device }}=I_{50 \Omega}\right.$ $\left.=V_{50 \Omega} / 50\right)$ oscillations for $V_{S}=1.2 \mathrm{~V}(2 \mu \mathrm{s})$ directly after a measurement of the $I-V$ characteristic in Figure 1(b). This shows stable waveforms with six oscillation periods as a result of repetitive switching and relaxation. The fundamental frequency of the oscillator here is $\sim 3.5 \mathrm{MHz}$. The current waveform in one oscillation period consists of two parts: a rapid current spike followed by a slower decay. It is expected that each spike component is related to the IMT/MIT transition of the threshold switching device, where the device changes between a low-current insulator state and highcurrent metal state. However, the peak-to-peak amplitudes of the current waveforms $\left(\Delta I_{\text {peak-to-peak }}\right)$ were measured as $\sim 0.4 \mathrm{~mA}$, which is $\sim 21 \%$ of the difference between the $I_{t h}$ and $I_{h}\left(\Delta I=I_{h}-I_{t h}=1.9 \mathrm{~mA}\right)$. This is not the case in $\mathrm{VO}_{2}$ devices reported by Kim et al., ${ }^{13}$ where the $\Delta I_{\text {peak-to-peak }}$ is almost the same as $\Delta I$. This difference is related to the ratio between $C_{\text {Device }}$ and $C_{\text {Parasitic }}$ in the circuit and will be discussed further in Sec. IV. 


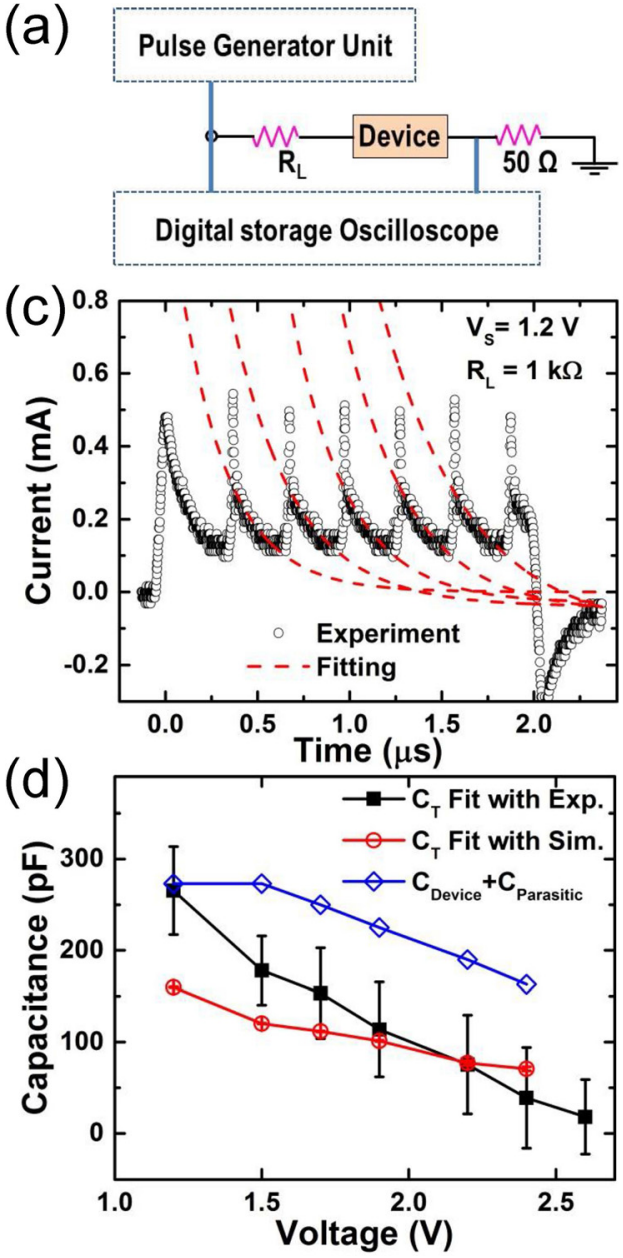

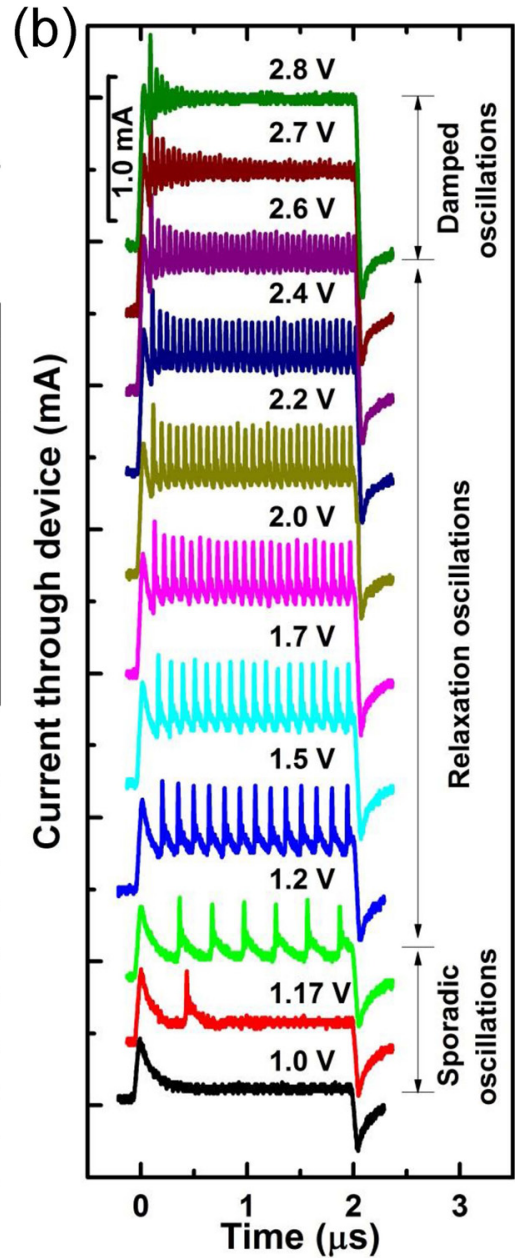

FIG. 2. (a) Schematic of the electrical circuit used to study the dynamics of self-oscillation when exciting the $\mathrm{NbO}_{x}$ device with rectangle voltage pulses. (b) Measured oscillation waveform of the device current $\left(I_{\text {Device }}\right)$ in the $50 \Omega$ resistor for $2 \mu$ s source voltage $\left(V_{S}\right)$ pulses in the range from 1.0 to $2.8 \mathrm{~V}$ and a series resistor of $1 \mathrm{k} \Omega$. (c) The decay part of the current waveform with fitted exponential decay curves from simple circuit analysis. (d) The total capacitance $C_{T}$ determined from fits to experimental and simulated waveforms, and the sum of the simulated device capacitance $C_{\text {Device }}$ and circuit capacitance $C_{\text {Parasitic }}$ as a function of the source voltage.
The decay part of the current oscillation can be fitted with an exponential decay curve derived from simple circuit analysis ${ }^{10,13}$

$$
I_{\text {Device }} \propto V_{S}\left[1+\frac{R_{D}}{R_{L}+50} \exp \left(-\frac{t-t_{0}}{\tau}\right)\right],
$$

where $I_{\text {Device }}$ is the current across the device, $V_{s}$ is the source voltage, and $\tau=R_{T} C_{T}$ is the time constant of the circuit, where $R_{T}=\frac{R_{D}\left(R_{L}+50\right)}{R_{D}+R_{L}+50}$ is the overall resistance in the circuit, and $C_{T}$ is the overall capacitance associated with $C_{\text {Device }}$ and $C_{\text {Parasitic. }}$ In Figure 2(c), the red dashed lines show fits to the data with the exponential decay curve of Equation (1). Based on the fitted results, $C_{T}$ was estimated as $\sim 265 \mathrm{pF}$ for a bias voltage of $1.2 \mathrm{~V}$ and was found to decrease with the increasing voltage, as shown in Figure 2(d). A similar phenomenon of negative differential capacitance has also been observed in $\mathrm{VO}_{2}$ films ${ }^{13}$ and interpreted as an increase in the fraction of metallic nano-domains within the switching region with increasing voltage. Further deep experiments are needed to clarify the origin of the phenomenon in the $\mathrm{NbO}_{x}$ devices.

\section{SIMULATION AND DISCUSSION}

Pickett and Williams established a simple analytical model of threshold switching based on Joule heating of a volume that undergoes an insulator-to-metal transition, and used a SPICE simulation to obtain good agreement with the experimental measurements of the static and dynamic behaviour of devices. ${ }^{7}$ However, a large departure between the experimental and the model $I-V$ curves was observed, especially in the low current region below the threshold voltage. ${ }^{7}$ This departure was believed to arise from the most aggressive assumption of their model where the electrical resistance of the insulating phase is linear and temperature independent, and the temperature within the metallic filament is constant. Furthermore, using these simple material and geometric parameters, this model fails to adequately describe our data, in particular, the feature of the NDR region in the static current-sweeping $I-V$ curves (see Figure S4 in supplementary material). To address these limitations and more accurately describe Joule heating and thermal transport between the metallic filament and the surrounding device, a numerical model based on the finite element method is presented for threshold switching.

To reproduce the $I-V$ curves in Figure 1(b), a two dimensional (2-D) axis-symmetric finite element simulation model was solved self-consistently in a time-dependent solver. In relation to our micro-meter sized devices with $75 \mathrm{~nm}$ thick films and the high compliance current ( 20 mA) forming process, ${ }^{37}$ the model considers a $\mathrm{NbO} / \mathrm{NbO}_{2}$ current channel (filament) surrounded by oxygen-deficient $\mathrm{Nb}_{2} \mathrm{O}_{5-x}$ as the simulated cell, where the effective $\mathrm{NbO}_{2}$ zone is a small active region with $100 \mathrm{~nm}$ diameter and $30 \mathrm{~nm}$ 
(a)

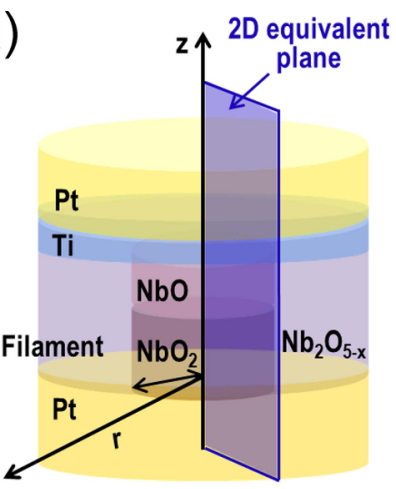

(c)

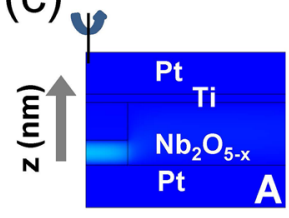

(b)
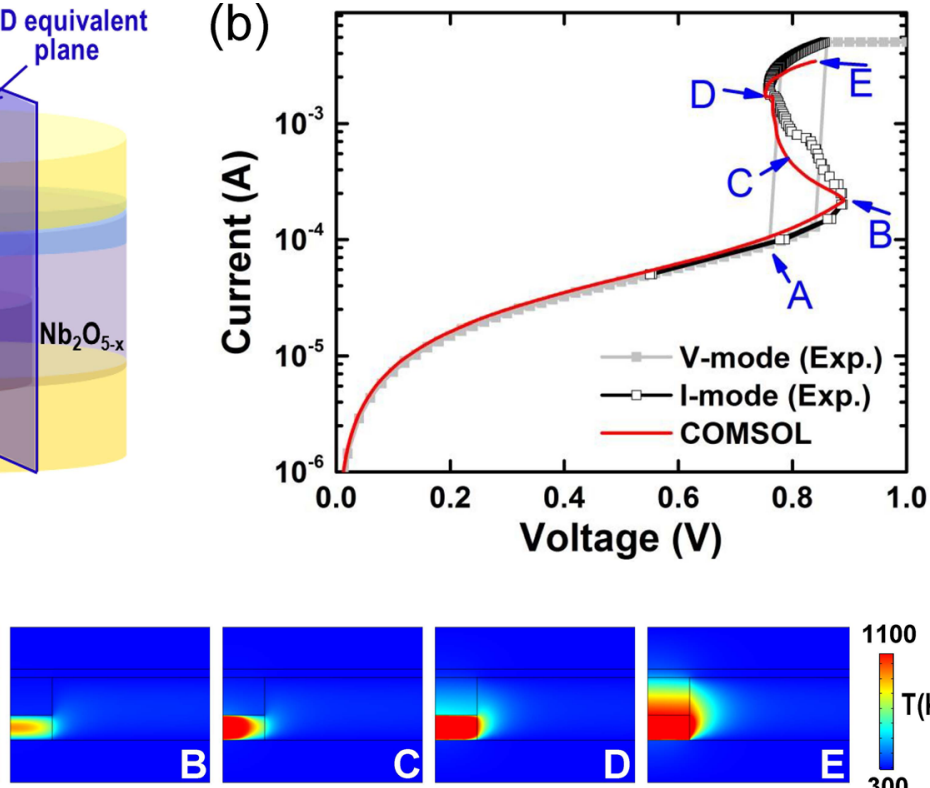
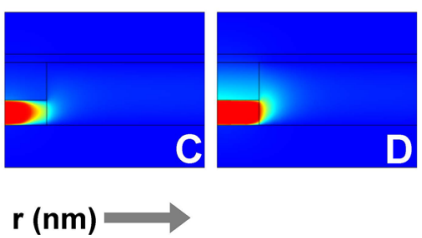

D

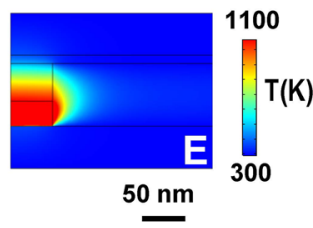

FIG. 3. (a) Geometry of the simulated device structure assuming a cylindrical conductive channel (filament) comprised of $\mathrm{NbO} / \mathrm{NbO}_{2}$ zones and surrounded by an $\mathrm{Nb}_{2} \mathrm{O}_{5-x}$ matrix. (b) The comparison of simulated and experimental $I-V$ characteristics of $\mathrm{Pt} /$ $\mathrm{Ti} / \mathrm{NbO}_{x} / \mathrm{Pt}$ devices. (c) Calculated 2-D maps of temperature for states A, B, C, $\mathrm{D}$, and $\mathrm{E}$ as depicted in the $I-V$ curve of the simulation results. The red color represents the high-temperature metallic regions during the IMT. thickness, as shown in Figure 3(a). The threshold switching response of $\mathrm{NbO}_{2}$ is assumed to result from a thermally induced IMT as proposed by Pickett and Williams. ${ }^{7}$ The time-dependent heat equation is solved, along with the continuity equation for temperature $T$ and potential $V,{ }^{24,44}$ i.e.,

$$
\begin{gathered}
\rho_{m} C_{p} \partial T / \partial t-\nabla k \nabla T=J^{2} / \sigma, \\
\nabla J=\nabla \sigma \nabla V=0,
\end{gathered}
$$

where $\rho_{m}, C_{p}, k, J$, and $\sigma$ denote mass density, heat capacity, thermal conductivity, local current density, and electric conductivity, respectively. The $k$ and $\sigma$ values of $\mathrm{NbO}_{2}$ film depend on device temperature and its conduction state. Simply, we use $k_{\text {insulator }}=0.07, k_{\text {metal }}=1.5 \mathrm{~W} \mathrm{~m}^{-1} \mathrm{~K}^{-1}$, and $\sigma_{\text {insulator }}=\sigma_{o} \exp \left(-E_{A C} / k_{B} T\right), \quad \sigma_{\text {metal }}=1 \times 10^{4} \Omega^{-1} \mathrm{~m}^{-1}$. Here, $\sigma_{o}$ is a pre-exponential factor, and $E_{\mathrm{AC}}$ is the activation energy for carrier transport. We further assumed that the $\mathrm{Nb}_{2} \mathrm{O}_{5-x}$ zone represented the high resistance state of the memory, ${ }^{45}$ and that the temperature dependence of $k$ and $\sigma$ were given by: $\sigma_{\mathrm{Nb}_{2} \mathrm{O}_{5}}=\sigma_{o} \exp \left(-E_{A C} / k_{B} T\right)$ and $k_{\mathrm{Nb}_{2} \mathrm{O}_{5}}$ $=k_{t h 0}\left(1+\lambda\left(T-T_{0}\right)\right)$, where $\sigma_{o}=100 \Omega^{-1} \mathrm{~m}^{-1}, \quad E_{A C}$ $=0.048 \mathrm{eV}, k_{t h 0}=0.035 \mathrm{~W} \mathrm{~m}{ }^{-1} \mathrm{~K}^{-1}$, and $\lambda=0.01 \mathrm{~K}^{-1}$. The $k$ and $\sigma$ values of the $\mathrm{NbO}$ zone represented the low resistance state of the memory, and were assumed as $\sigma_{\mathrm{NbO}}=$ $7.5 \times 10^{4} \Omega^{-1} \mathrm{~cm}^{-1}$ and $k_{\mathrm{NbO}}=10 \mathrm{~W} \mathrm{~m}^{-1} \mathrm{~K}^{-1}{ }^{45}$ For the $k$ and $\sigma$ values of $\mathrm{Pt}$ and $\mathrm{Ti}$ and other used material parameters such as mass density and heat capacity, we used the build-in material parameters in COMSOL software.

The $T_{\text {IMT }}$ for thermally induced phase transitions in transition metal oxides can differ during heating and cooling branches. ${ }^{16}$ However, no such hysteresis is reported for $\mathrm{NbO}_{2}$ films. ${ }^{17}$ To simplify the analysis, we therefore assumed the same transition temperature in the calculation, with the IMT transition modelled by temperature-dependent thermal and electrical conductivities that vary between those of the insulating and metallic phases over a temperature range of $100 \mathrm{~K}$, centered at the nominal transition temperature of $1073 \mathrm{~K}$. These parameters were chosen to match the published data on the IMT in $\mathrm{NbO}_{2} \cdot{ }^{7,24}$ This allowed a quantitative analysis of field and temperature contributions and accounts accurately for the CC-NDR characteristics of the DC response. ${ }^{24,46,47}$

\section{A. I-V characteristics}

The calculated $I-V$ characteristics for the best fit of the model to the experimental data are shown in Figure 3(b). Both the low and high current regions are matched reasonably well except a deviation in the multi-NDR region. The on/off ratio for the current jump across the transition is around one order of magnitude, which is close to the resistance change across the thermal transition in $\mathrm{NbO}_{2}$. The threshold and hold voltage points are $\left(V_{t h} \sim 0.89 \mathrm{~V} ; I_{t h}\right.$ $\sim 0.2 \mathrm{~mA})$ and $\left(V_{h} \sim 0.74 \mathrm{~V} ; I_{h} \sim 1.6 \mathrm{~mA}\right)$, respectively, where only the hold current is less than the experimental data $(2.1 \mathrm{~mA})$. Hence, this model can be used as a predictive tool for circuit design as well as for simulating the parametric behaviour of oxide threshold switching. Figure 3(c) shows the calculated 2-D map of temperature for states A, B, C, D, and E as labelled in Figure 3(b). Initially, at low biases, the device is resistive and the current conducts through the $\mathrm{NbO}_{2}$ zone, then the temperature increases with the increasing current due to Joule heating (A-B in Figure 3(c)). As the device current increases above $I_{t h}(\mathrm{~B}$ in Figure 3(c)), the conductivity of the filament decreases and the local IMT is induced in the central hot spot of $\mathrm{NbO}_{2}$ zone, as shown in the red color region, which results in the CC-NDR shown in the $I-V$ curve. A complete metallic $\mathrm{NbO}_{2}$ zone emerged around $I_{h}$ (D in Figure 3(c)), and as the current increases further, the $\mathrm{NbO}_{2}$ zone remains in the metallic state, and the temperature increases further (D-E in Figure 3(c)).

The $I-V$ curves for different devices show some variability due to the simple device structures employed (i.e., 
direct probing onto contact pads) and due to the statistical variability in the electro-forming process. The resulting $I-V$ curves can be fitted using the proposed IMT model by changing the "effective" geometry of the filament (i.e., the diameter and relative thickness of the filamentary oxide layers), as might be expected to result from different electroforming conditions. Indeed, the model has general applicability and can also be used to model devices with small active regions such as that in Pickett's paper. ${ }^{7}$ From an experimental perspective, improvements in uniformity have recently been demonstrated for $\mathrm{Pt} / \mathrm{NbO}_{x} / \mathrm{TiN}$ structures using more controlled electroforming (series resistance to reduce current overshoot).

Alternative models of the NDR response in $\mathrm{NbO}_{x}$ have also recently been proposed. ${ }^{28-30}$ These are based on the temperature and field dependence of $\mathrm{PF}$ conduction rather than the thermally induced IMT in crystalline $\mathrm{t}-\mathrm{NbO}_{2}{ }^{7,17}$ However, the calculated NDR response in these models critically depends on the assumed temperature and field dependence of the film conductivity as well as accurate modelling of local Joule heating. The uncertainty associated with these assumptions and the sensitivity of the calculated temperature rise to such parameters makes it difficult to distinguish between the various PF and IMT models. For example, the current IMT model can also generate the NDR response reported by Funck. ${ }^{30}$ Clearly, new experiments are required to identify the specific NDR mechanism in $\mathrm{NbO}_{x}$.

\section{B. Oscillation characteristics}

To simulate the dynamics of the device in an oscillator circuit, including the frequency and waveform of the device current, the model was extended to include circuit elements as shown in the schematic of Figure 4(a). To match the current oscillation curves, the parameters obtained by fitting the $I-V$ measurement of Figure 3(b) were used and the value of $C_{\text {Device }}$ and $C_{\text {Parasitic }}$ were adjusted. Here, the $C_{\text {Parasitic }}$ is marked in the circuit schematic, and plays an important role in determining the oscillation waveform.

As shown in Figure 4(b) for the case of $V_{S}=1.2 \mathrm{~V}$ $(2 \mu \mathrm{s})$ and $R_{L}=1 \mathrm{k} \Omega$, the model captures the periodicity and waveform of the oscillations and reproduces the experimental behaviour very well. The optimal value of $C_{\text {Device }}$ is $240 \mathrm{pF}$, which is close to the value determined from complex impedance spectra reported for micro-sized $\mathrm{NbO}_{x}$ devices, ${ }^{48}$ and the optimal value of $C_{\text {Parasitic }}$ is $33 \mathrm{pF}$, which is comparable to the measured open circuit capacitance of the measuring system. The calculations show that the current waveform is sensitive to the value of $C_{\text {Parasitic }}$. For example, for $C_{\text {Parasitic }}=0$, the current spike disappears, resulting in a sawtooth waveform with the same fundamental frequency, as shown by the green line included in Figure 4(b).

An expanded view of the current spike region is shown in Figure 4(c). Both the experimental and calculated off-toon-transition times are $\Delta t_{O N}=14 \mathrm{~ns}$, which is consistent with a previous experimental report ( $\sim 22 \mathrm{~ns})$ (Ref. 49) but

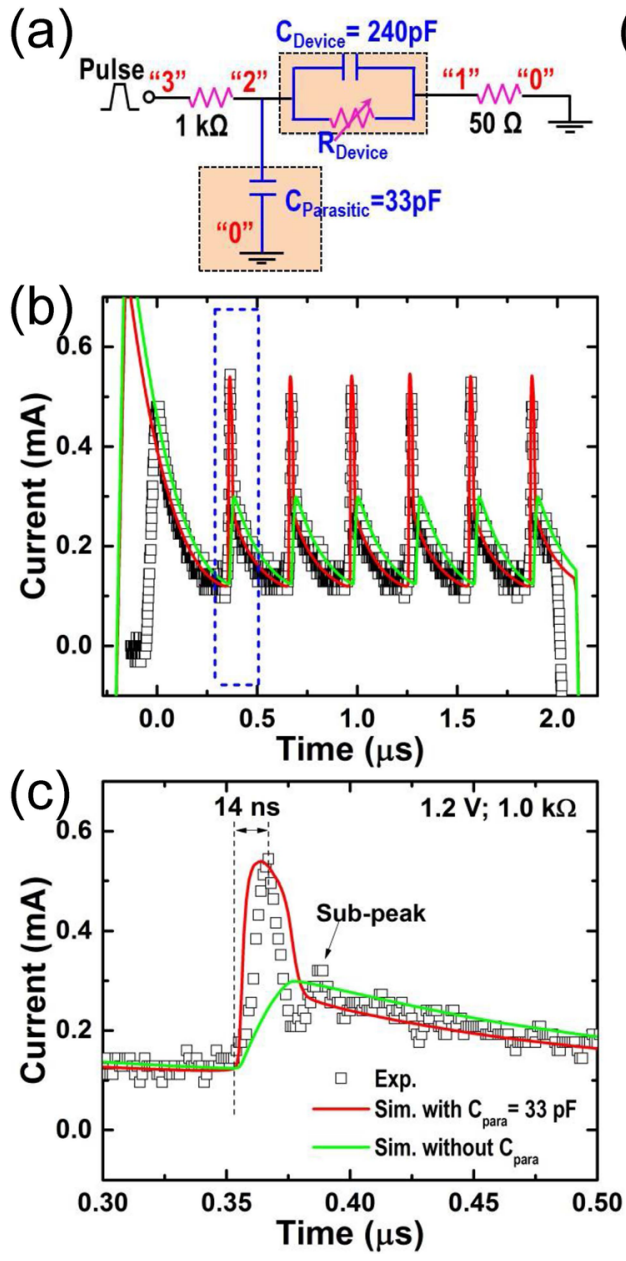

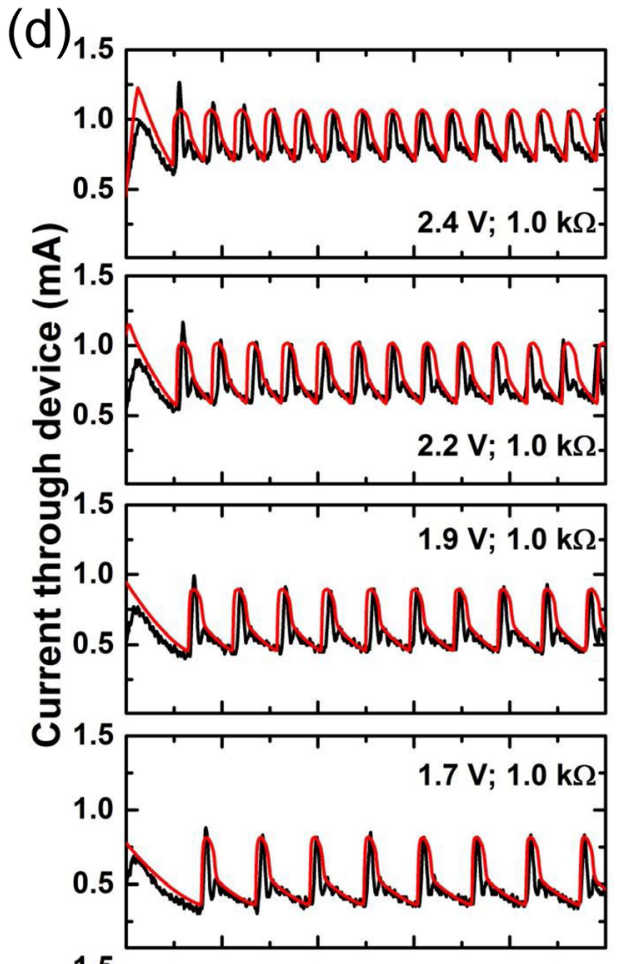

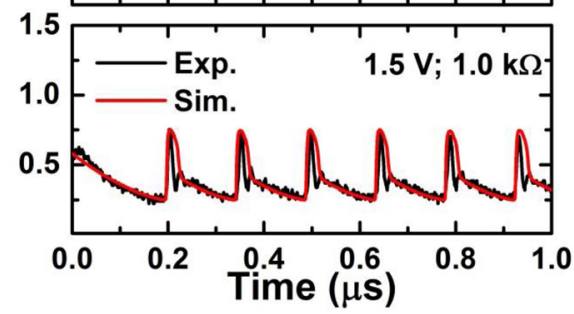

FIG. 4. (a) Schematic of the electrical circuit used in simulation to study the dynamics of self-oscillations. (b) Measured (black squares) and simulated (red curves) oscillation waveforms of the current through the $50 \Omega$ resistor for a source voltage of $V_{S}=1.2 \mathrm{~V}(2 \mu \mathrm{s})$ and the series resistance of $R_{L}=1 \mathrm{k} \Omega$. The green lines show the simulation data for $C_{\text {Parasitic }}$ $=0$ for comparison, where no current spike was observed in the current waveform. (c) Magnification of the dashed rectangle region in (b). (d) Measurements (black curves) and simulation (red curves) of time traces of the current through the device when excited with source voltages ranging from $1.5 \mathrm{~V}$ (bottom) to $2.6 \mathrm{~V}$ (top) with $1 \mathrm{k} \Omega$ series. 
the two orders of magnitude larger than that $(\sim 700 \mathrm{ps})$ reported by Pickett and Williams. ${ }^{7}$ This highlights the effect of the measurement system and device structure on the observed rise time. Measurement of the on-to-off-transition time is complicated in the present case by a sub-peak in the current oscillation which appears to result from the multi-NDR regions in the $I-V$ curves in Figure 1(b). An estimate of $\sim 4.0$ $\mathrm{pJ}$ for the total energy input during on-switching can be obtained by noting that the voltage across the device was $\sim 0.9 \mathrm{~V}$ and that numerical integration of the measured current over the transition time is $\sim 4.4 \mathrm{pC}$. This is more than one order of magnitude larger than that obtained from Pickett's experiments due to the energy consumption from the intrinsic parallel capacitance. $^{7}$

To match the measured pulse characteristics for other source voltages above $1.5 \mathrm{~V}$, first we fixed the two capacitances as $C_{\text {Device }}=240 \mathrm{pF}$ and $C_{\text {Parasitic }}=33 \mathrm{pF}$. As shown in Figure S5 (supplementary material), the simulated current waveforms deviate from the experimental data above $1.7 \mathrm{~V}$, i.e., the frequency and waveform of simulated curves do not match the experimental data for increasing source voltage. Considering the phenomenon of negative differential capacitance shown in Figure 2(d), we have adjusted the value of $C_{\text {Device }}$ and $C_{\text {Parasitic }}$ to match the measured oscillation waveforms for other source voltages in the range from 1.5 to $2.4 \mathrm{~V}$, as shown in Figure 4(d). The sum of $C_{\text {Device }}$ $+C_{\text {Parasitic }}$ was plotted in Figure 2(d) as a function of source voltages.

Moreover, we fitted our calculated waveforms with the exponential decay curve of Equation (1) from simple circuit analysis. Then the obtained $C_{T}$ for different $V_{S}$ shows the same trend as that from the experimental data, as shown in Figure 2(d). However, these calculated $C_{T}$ values are not equal to the sum of $C_{\text {Device }}+C_{\text {Parasitic }}$, due to circuit dynamics. For the voltage pulse of $2.6 \mathrm{~V}$, the simulated device current does not show oscillation behavior: this is due to the fact that the voltage exceeds the upper limit of the stable oscillation window, which is limited to the voltage range 1.1 to $2.5 \mathrm{~V}$ from load-line analysis of the calculated $I-V$ curve in Figure 3(b). This model can also be used to simulate other measured pulse characteristics for different source voltages with of $R_{L}=500 \Omega, 2 \mathrm{k} \Omega$, and $4 \mathrm{k} \Omega$, as can be seen in Figure S6 (supplementary material).

\section{Voltage/current waveforms and limit cycles}

To better understand the device behaviour and the dynamics associated with oscillations, Figure 5(a) shows the relationship between the device voltage $V_{\text {Device }}$ and various current components for a single oscillation period in terms of simulation data for $V_{S}=1.2 \mathrm{~V}$. The latter include the current due to the resistance of the device $\left(I_{R_{-} \text {device }}\right)$, the current due to the capacitance of device $\left(I_{C_{-} \text {device }}\right)$, the total device current $I_{\text {Device }}$, and the current due to parasitic capacitance $\left(I_{C_{-} \text {parasitic }}\right)$. The sequential charging and discharging stages are evident in the $V_{\text {Device }}$ trace which is related to the low and high current regions of the $I_{R_{-} \text {device }}$ signal. Note that $I_{R_{-} \text {device }}$ is positive while $I_{C_{-} \text {device }}$ is negative, and the sum of the two currents is the current through the device: $I_{\text {Device }}$
$=I_{R_{-} \text {device }}+I_{C_{-} \text {device }}$. This is the origin of the deviation mentioned above where the $\Delta I_{\text {peak-to-peak }}$ is less than the current difference between the $I_{t h}$ and $I_{h}$. The oscillation waveforms for the total device current have a roughly trapezoidal shape, which is also observed in the other reported experiments. ${ }^{6,750}$ The current through the parasitic capacitance, $I_{C_{\text {_parasitic }}}$ is also negative due to the charging and discharging of $C_{\text {Parasitic }}$, which also influences the waveform of $I_{\text {Device }}$. As a consequence, the peak of $I_{\text {Device }}$ occurs concurrently with the minimum of $I_{C \_p a r a s i t i c}$, but it has $\sim 6 \mathrm{~ns}$ delay compared with the maximum of $I_{R_{-} \text {device }}$, as shown in Figure 5(a). Consequently, the oscillation frequency, the waveform of $I_{\text {Device}}$, the peak-to-peak current amplitude, and even the off-to-on-transition time are affected by $C_{\text {Device }}$ and $C_{\text {Parasitic }}$, as discussed later.

Replotting the $I_{\text {Device }}-V_{\text {Device }}$ response for $V_{S}=1.2 \mathrm{~V}$ defines a limit cycle as shown by the red line in Figure 5(b), which is a characteristic of self-sustained oscillators. ${ }^{27,51,52}$ The $I_{R_{-} \text {device }}-V_{\text {Device }}$ response (blue line) is also plotted in Figure 4(b), and is shown to roughly match the hysteresis region of the voltage sweeping $I-V$ curves (dashed line). In relation to the current sweeping $I-V$ curves (dotted line), four characteristic points for a cycle of $I_{R_{-} \text {device }}$ oscillation are marked in Figure 5(b), which corresponds to those in Figure 3(b). Region B-E represents the IMT, E-D corresponds to the device in a metallic state, D-A represents the MIT, and A-B corresponds to the device in its insulating state. The oscillation mechanism can then be described as follows: (a) Starting from the threshold-bias point B, the current rises to the on-state point $\mathrm{E}$ upon switching as a result of the total capacitance $\left(C_{T}\right)$ in the circuit; (b) the current decreases to point $\mathrm{D}$ of the $I_{R_{-} \text {device }}-V_{\text {Device }}$ characteristic as the capacitance discharges, and then, the current falls to the off-state point A due to the MIT; (c) then the voltage increases as the capacitance charges, and a new cycle of oscillation begins once the threshold-bias point B is reached, where the conditions for the onset of oscillating behaviour are satisfied again.

The corresponding four characteristic points are also marked in Figure 5(a) to determine the IMT/MIT transition time. The rise time of $14 \mathrm{~ns}$ from $\mathrm{B}$ to $\mathrm{E}$ in the simulation of $I_{R_{-} \text {device }}$ and $I_{\text {Device }}$ is consistent with the experimental value as shown in Figure 4(c). Here, each spike component can be related to the IMT(B-E), metal (E-D), and MIT (D-A), while each decay component can be related to the insulator state (A-B) of the device. The corresponding time was defined as $t_{\mathrm{IMT}}, t_{\mathrm{metal}}, t_{\mathrm{MIT}}$, and $t_{\text {insulator. }}$. For the case of $V_{S}=1.2 \mathrm{~V}$ and $R_{L}=1 \mathrm{k} \Omega$, the oscillation period is $T_{\mathrm{Osc}}=t_{\mathrm{IMT}}+t_{\text {metal }}$ $+t_{\mathrm{MIT}}+t_{\text {insulator }}=14+17+10+266=307 \mathrm{~ns}$. All four stages can be tuned by appropriate control of the bias voltage, a series resistor, and an external capacitance. The oscillation frequency $f_{\mathrm{Osc}}$ can be tuned accordingly.

Similarly, the $I_{\text {Device }}-V_{\text {Device }}$ response for $V_{S}=2.2 \mathrm{~V}$ and $R_{L}=1 \mathrm{k} \Omega$, also defines a limit cycle as shown by the red line in Figure 5(c). In relation to the voltage sweeping $I-V$ curves (dashed line), the $I_{R \_ \text {device }}-V_{\text {Device }}$ response represents a deformed hysteresis region as shown by the blue line in Figure 5(c), which is a dynamic feature due to the high frequency. Note that if the $C_{\text {Parasitic }}=0$, the limit cycle 
(a)

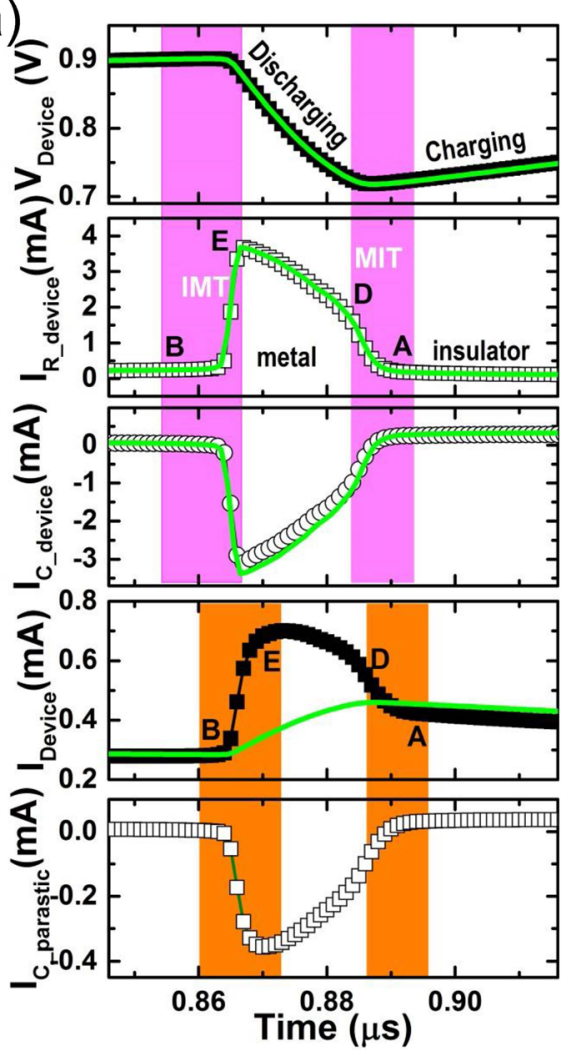

(b)

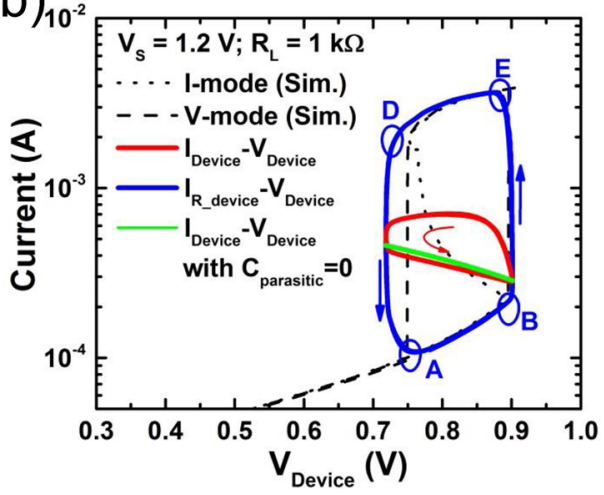

(c)

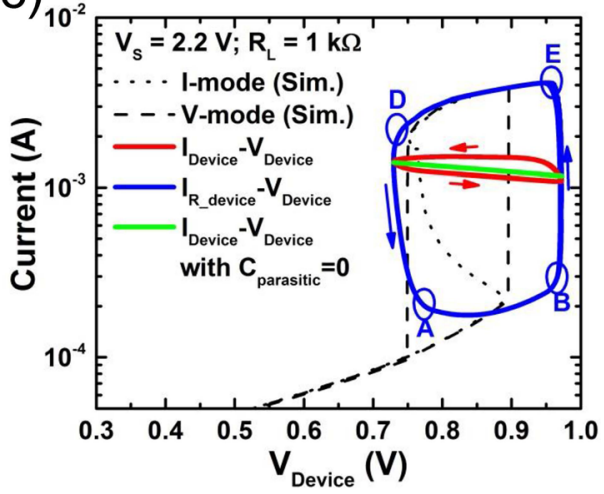

FIG. 5. (a) Calculated device voltage, $V_{\text {Device }}$, and related current components: $I_{R_{-} \text {device }}, I_{C_{-} \text {device }}, I_{\text {Device }}$, and $I_{C \_ \text {parasitic }}$ for a source voltage of $V_{S}=1.2 \mathrm{~V}$ and load resistance of $R_{L}=1 \mathrm{k} \Omega$. (b) and (c) Show the limit cycles of $I_{\text {Device }}$ $-V_{\text {Device }}$ (red lines) for $V_{S}=1.2 \mathrm{~V}$ and $2.2 \mathrm{~V}$, respectively. The green lines show the simulation data of $I_{\text {Device }}$ $-V_{\text {Device }}$ with $C_{\text {Parasitic }}=0$, where the limit cycles collapse to straight lines. The blue lines show the $I_{R_{-} \text {device }}$ $-V_{\text {Device }}$ characteristics. The black lines show the $I \sim V$ response of the device under voltage-controlled (dashed) and current-controlled (dotted) operation for comparison. collapses to a straight line for both $V_{S}=1.2 \mathrm{~V}$ and $2.2 \mathrm{~V}$ case with $R_{L}=1 \mathrm{k} \Omega$, as shown by the green lines in Figures 5(b) and 5(c).

\section{Capacitance dependence on $\Delta I_{\text {peak }}-t o-p e a k$ and frequency}

The tunability of this $\mathrm{Ti} / \mathrm{NbO}_{x}$ oscillator, including the effect of device and parasitic capacitances on the operating frequency, is explored through two sets of simulations: (1) $C_{\text {Device }}$ is varied from $1 \mathrm{pF}$ to $2 \mathrm{nF}$ and the other parameters are kept constant $\left(V_{S}=1.2 \mathrm{~V}, R_{L}=1 \mathrm{k} \Omega\right.$, and $C_{\text {Parasitic }}$ $=33 \mathrm{pF}$ ); (2) $C_{\text {Parasitic }}$ is varied from $1 \mathrm{pF}$ to $5 \mathrm{nF}$ and the other parameters are kept constant $\left(V_{S}=1.2 \mathrm{~V}, R_{L}=1 \mathrm{k} \Omega\right.$, and $C_{\text {Device }}=240 \mathrm{pF}$ ). Results show that both the oscillation wave shape and frequency depend strongly on $C_{\text {Device }}$ and $C_{\text {Parasitic }}$. Figures 6(a) and 6(b) show the current-time characteristics of simulated, self-sustained oscillations for various capacitance values, where the effects of capacitance can be clearly observed. The peak-to-peak amplitudes of the total device current $\left(\Delta I_{\text {peak-to-peak }}\right)$ decrease significantly when $C_{\text {Device }}$ reaches $500 \mathrm{pF}$ (Figure 6(a)), since a larger device capacitance stores and discharges more charge. By increasing $C_{\text {Device }}, I_{C_{-} \text {device }}$ increases accordingly and $\Delta I_{\text {peak-to-peak }}$ decreases. In contrast, $\Delta I_{\text {peak-to-peak }}$ increases significantly when $C_{\text {Parasitic }}$ changes from $1 \mathrm{pF}$ to $1 \mathrm{nF}$ (Figure $6(\mathrm{~b})$ ). Finally, $\Delta I_{\text {peak-to-peak }}$ increases proportionally with the ratio of $C_{\text {Parasitic }}$ and $C_{\text {Device }}$ and then tends to saturate, as shown in Figure 6(c).

It is believed that the transition between the insulating and the metallic phase in $\mathrm{NbO}_{2}$ results from a thermally induced Mott-Peierls transition in which the $\mathrm{NbO}_{2}$ lattice undergoes a structural transition from a distorted (insulating) rutile structure at low temperatures to an undistorted (metallic) rutile structure at high temperatures. ${ }^{53}$ The physical transition times in a nanoscale $\mathrm{NbO}_{2}$ device between $\boldsymbol{o n}$ and $\boldsymbol{o f f}$ states have been reported to be $\sim 700$ ps for the IMT and $2.3 \mathrm{~ns}$ for $\mathrm{MIT}^{7}{ }^{7}$ which indicates that the maximum achievable frequency for these oscillators is expected to be $\sim \mathrm{GHz}$. However, the oscillation frequency is determined by the resistor-capacitor time constant associated with charging/discharging, and in most cases, the peak frequency is limited by $C_{\text {Parasitic }}$ and $C_{\text {Device }}$. Figure $6(\mathrm{~d})$ indicates that the frequency is inversely proportional to the sum of $C_{\text {Parasitic }}$ and $C_{\text {Device }}$. To increase the frequency, clearly both the $C_{\text {Parasitic }}$ and $C_{\text {Device }}$ should be reduced. This suggested as the advantage of nanoscale devices for high-frequency operation.

\section{CONCLUSION}

The electrical self-oscillation behaviour of an $\mathrm{NbO}_{x} \mathrm{CC}$ NDR device was investigated experimentally and with reference to a finite element model of the switching response based on a thermally induced IMT. Room temperature electrical oscillation was demonstrated for a circuit containing the $\mathrm{NbO}_{x}$ device, and shown to be directly related to the presence of the NDR region in the $I-V$ characteristic of the device operated in the current mode. Devices were further shown to display sporadic, relaxation, and damped oscillations depending on the applied voltage and series resistance. A Joule-heating induced electro-thermal threshold switching model based on the finite element method was presented and shown to reproduce the $I-V$ characteristic of the device. Based on this model, the switching dynamics of the electrical 

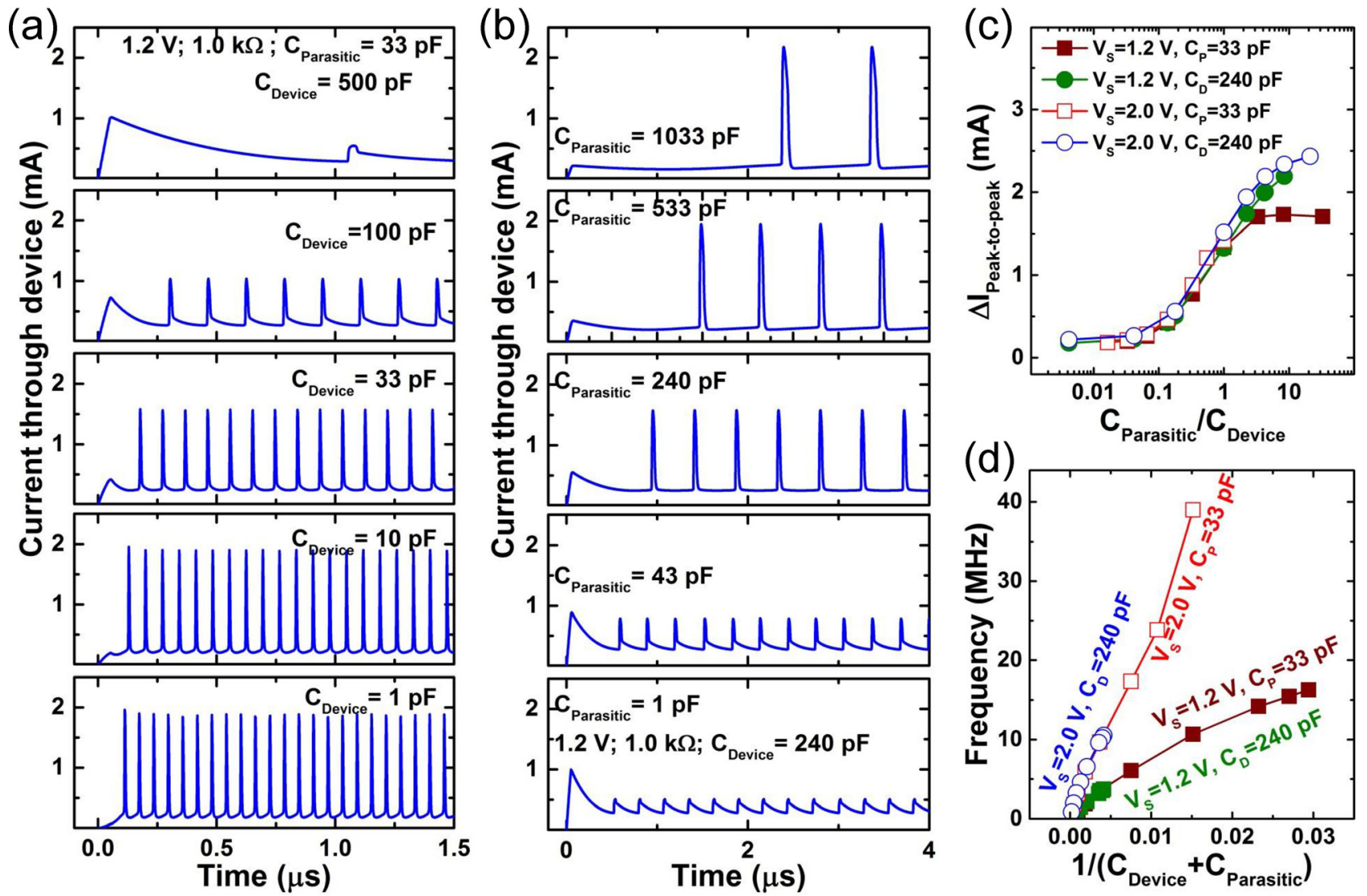

FIG. 6. (a) Waveforms of $I_{\text {Device }}$ as a function of the device capacitance $C_{\text {Device }}$, and (b) as a function of the parasitic capacitance $C_{P a r a s i t i c}$. (c) The dependence of the peak-to-peak device current on the ratio of $C_{\text {Parasitic }} / C_{\text {Device. }}$. (d) The dependence of the oscillation frequency on the sum of $C_{\text {Device }}$ and $C_{\text {Parasitic }}$.

circuit which included the CC-NDR device were investigated. The waveform of the device voltage and current were discussed in detail with reference to the model predictions. The model highlighted the role of parasitic and device capacitance in controlling the oscillation frequency and current amplitude. Finally, it is expected that physics-based finite element models can be used to explore oscillator coupling and associated synchronization behaviour.

\section{SUPPLEMENTARY MATERIAL}

See supplementary material for the complete experimental and simulated oscillation waveforms of the studied $\mathrm{NbO}_{x}$ devices.

\section{ACKNOWLEDGMENTS}

This research reported in this publication was supported by funding from the Australian Research Council. We would also like to acknowledge and thank Australian Nanotechnology Fabrication Facility (ANFF) ACT node for access to research facility and technical expertise.

${ }^{1}$ J. J. Yang, D. B. Strukov, and D. R. Stewart, Nat. Nanotechnol. 8, 13 (2013).

${ }^{2}$ S. D. Ha, J. Shi, Y. Meroz, L. Mahadevan, and S. Ramanathan, Phys. Rev. Appl. 2, 064003 (2014).

${ }^{3}$ S. Datta, N. Shukla, M. Cotter, A. Parihar, and A. Raychowdhury, in Proceedings of 51st ACM/EDAC/IEEE Design Automation Conference (DAC) (2014), pp. 1-6.
${ }^{4}$ M. D. Pickett, G. Medeiros-Ribeiro, and R. S. Williams, Nat. Mater. 12, 114 (2013).

${ }^{5}$ N. Shukla, A. Parihar, E. Freeman, H. Paik, G. Stone, V. Narayanan, H. Wen, Z. Cai, V. Gopalan, and R. Engel-Herbert, Sci. Rep. 4, 4964 (2014). ${ }^{6}$ T. C. Jackson, A. Sharma, J. Bain, J. Weldon, and L. Pileggi, IEEE J. Emerging Sel. Top. Circuits Syst. 5, 230 (2015).

${ }^{7}$ M. D. Pickett and R. S. Williams, Nanotechnology 23, 215202 (2012).

${ }^{8}$ Z. Yang, C. Ko, and S. Ramanathan, Annu. Rev. Mater. Res. 41, 337 (2011).

${ }^{9}$ N. Shukla, T. Joshi, S. Dasgupta, P. Borisov, D. Lederman, and S. Datta, Appl. Phys. Lett. 105, 012108 (2014).

${ }^{10}$ Y. W. Lee, B.-J. Kim, J.-W. Lim, S. J. Yun, S. Choi, B.-G. Chae, G. Kim, and H.-T. Kim, Appl. Phys. Lett. 92, 162903 (2008).

${ }^{11}$ J. Leroy, A. Crunteanu, J. Givernaud, J.-C. Orlianges, C. Champeaux, and P. Blondy, Int. J. Microwave Wireless Technol. 4, 101 (2012).

${ }^{12}$ J. Sakai, J. Appl. Phys. 103, 103708 (2008).

${ }^{13}$ H.-T. Kim, B.-J. Kim, S. Choi, B.-G. Chae, Y. W. Lee, T. Driscoll, M. M. Qazilbash, and D. Basov, J. Appl. Phys. 107, 023702 (2010).

${ }^{14}$ M. S. Mian, K. Okimura, and J. Sakai, J. Appl. Phys. 117, 215305 (2015).

${ }^{15}$ A. Beaumont, J. Leroy, J.-C. Orlianges, and A. Crunteanu, J. Appl. Phys. 115, 154502 (2014).

${ }^{16}$ S. Kumar, M. D. Pickett, J. P. Strachan, G. Gibson, Y. Nishi, and R. S. Williams, Adv. Mater. 25, 6128 (2013).

${ }^{17}$ R. Janninck and D. Whitmore, J. Phys. Chem. Solids 27, 1183 (1966).

${ }^{18}$ A. B. Posadas, A. O'Hara, S. Rangan, R. A. Bartynski, and A. A. Demkov, Appl. Phys. Lett. 104, 092901 (2014).

${ }^{19}$ D. Geppert, Proc. IEEE 51, 223 (1963).

${ }^{20}$ K. Chopra, Proc. IEEE 51, 941 (1963).

${ }^{21}$ B. Lalevic and M. Shoga, Thin Solid Films 75, 199 (1981).

${ }^{22}$ X. Liu, S. M. Sadaf, M. Son, J. Shin, J. Park, J. Lee, S. Park, and H. Hwang, Nanotechnology 22, 475702 (2011).

${ }^{23}$ X. Liu, S. M. Sadaf, M. Son, J. Park, J. Shin, W. Lee, K. Seo, D. Lee, and H. Hwang, IEEE Electron Device Lett. 33, 236 (2012).

${ }^{24}$ X. Liu, S. K. Nandi, D. K. Venkatachalam, K. Belay, S. Song, and R. G. Elliman, IEEE Electron Device Lett. 35, 1055 (2014). 
${ }^{25}$ W. Yuhan, R. B. Comes, S. A. Wolf, and L. Jiwei, IEEE J. Electron Devices Soc. 4, 11 (2016).

${ }^{26}$ S. Li, X. Liu, S. K. Nandi, D. K. Venkatachalam, and R. G. Elliman, Appl. Phys. Lett. 106, 212902 (2015).

${ }^{27}$ A. Ascoli, S. Slesazeck, H. Mahne, R. Tetzlaff, and T. Mikolajick, IEEE Trans. Circuits Syst. I Regul. Pap. 62, 1165 (2015).

${ }^{28}$ S. Slesazeck, H. Mähne, H. Wylezich, A. Wachowiak, J. Radhakrishnan, A. Ascoli, R. Tetzlaff, and T. Mikolajick, RSC Adv. 5, 102318 (2015)

${ }^{29}$ G. A. Gibson, S. Musunuru, J. Zhang, K. Vandenberghe, J. Lee, C.-C. Hsieh, W. Jackson, Y. Jeon, D. Henze, Z. Li, and R. S. Williams, Appl. Phys. Lett. 108, 023505 (2016).

${ }^{30}$ C. Funck, S. Menzel, N. Aslam, H. Zhang, A. Hardtdegen, R. Waser, and S. Hoffmann-Eifert, Adv. Electron. Mater. 2, 1600169 (2016).

${ }^{31}$ F. Chudnovskii, L. Odynets, A. Pergament, and G. Stefanovich, J. Solid State Chem. 122, 95 (1996).

${ }^{32}$ S. Shin, T. Halpern, and P. Raccah, J. Appl. Phys. 48, 3150 (1977).

${ }^{33}$ J. Park, E. Cha, I. Karpov, and H. Hwang, Appl. Phys. Lett. 108, 232101 (2016).

${ }^{34}$ B. Boiko, P. Pancheha, V. Kopach, and Y. L. Pozdeev, Thin Solid Films 130, 341 (1985).

${ }^{35}$ J. Lee, E. Cha, Y. Kim, B. Chae, J. Kim, S. Lee, H. Hwang, and C. Park, Micron 79, 101 (2015).

${ }^{36}$ M. Vos, X. Liu, P. L. Grande, S. K. Nandi, D. K. Venkatachalam, and R. G. Elliman, Nucl. Instrum. Methods Phys. Res., Sect. B 340, 58 (2014).

${ }^{37} \mathrm{~S}$. Li, X. Liu, S. Nandi, D. Venkatachalam, and R. Elliman, in Proceedings of 2014 Conference on Optoelectronic and Microelectronic Materials Devices (COMMAD) (2014), p. 138-140.

${ }^{38}$ G. Taylor and B. Lalevic, Solid-State Electron. 19, 669 (1976).
${ }^{39}$ Z. Yang, C. Ko, and S. Ramanathan, J. Appl. Phys. 108, 073708 (2010).

${ }^{40}$ Y. Chang, C. Koo, J. Yang, Y. Kim, D. Kim, J. Lee, T. Noh, H.-T. Kim, and B. Chae, Thin Solid Films 486, 46 (2005).

${ }^{41}$ J. Rozen, R. Lopez, R. F. Haglund, and L. C. Feldman, Appl. Phys. Lett. 88, 081902 (2006).

${ }^{42}$ S. Pearson and H. S. G. Anson, Proc. Phys. Soc. London 34, 204 (1921).

${ }^{43}$ P. E. Schmidt and R. C. Callarotti, J. Appl. Phys. 55, 3144 (1984).

${ }^{44}$ C. Hermes, M. Wimmer, S. Menzel, K. Fleck, G. Bruns, M. Salinga, U. Bottger, R. Bruchhaus, T. Schmitz-Kempen, and M. Wuttig, IEEE Electron Device Lett. 32, 1116 (2011).

${ }^{45}$ X. Liu, S. Nandi, D. Venkatachalam, S. Li, K. Belay, and R. Elliman, in Proceedings of 2014 Conference on Optoelectronic and Microelectronic Materials Devices (COMMAD) (2014), pp. 280-282.

${ }^{46}$ S. K. Nandi, X. Liu, D. K. Venkatachalam, and R. G. Elliman, J. Phys. D: Appl. Phys. 48, 195105 (2015).

${ }^{47}$ S. K. Nandi, X. Liu, D. K. Venkatachalam, and R. G. Elliman, Appl. Phys. Lett. 107, 132901 (2015).

${ }^{48}$ H. Wylezich, H. Mähne, J. Rensberg, C. Ronning, P. Zahn, S. Slesazeck, and T. Mikolajick, ACS Appl. Mater. Interfaces 6, 17474 (2014).

${ }^{49}$ S. Kim, X. Liu, J. Park, S. Jung, W. Lee, J. Woo, J. Shin, G. Choi, C. Cho, S. Park, D. Lee, E. Cha, B. Lee, H. Lee, S. Kim, S. Chung, and H. Hwang, in Symposium on Very Large Scale Integration Technology (VLSIT) (2012), pp. 155-156

${ }^{50}$ Q. Gu, A. Falk, J. Wu, L. Ouyang, and H. Park, Nano Lett. 7, 363 (2007).

${ }^{51}$ S. Lavizzari, D. Ielmini, and A. L. Lacaita, IEEE Trans. Electron Devices 57, $1838(2010)$.

${ }^{52}$ A. Cywar, F. Dirisaglik, M. Akbulut, G. Bakan, S. Steen, H. Silva, and A. Gokirmak, IEEE Electron Device Lett. 32, 1486 (2011).

${ }^{53}$ A. O'Hara, T. N. Nunley, A. B. Posadas, S. Zollner, and A. A. Demkov, J. Appl. Phys. 116, 213705 (2014). 